\title{
It Is Not Necessary to Discontinue Seizure Threshold-Lowering Medications Prior to Myelography
}

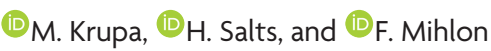

\begin{abstract}
BACKGROUND AND PURPOSE: There is no consensus on whether patients undergoing myelography should discontinue medications that could lower their seizure threshold. The purpose of this study was to document the most commonly prescribed seizure thresholdlowering medications in patients undergoing myelography and determine whether withholding such medications decreases the incidence of seizures.
\end{abstract}

MATERIALS AND METHODS: We performed a retrospective observational study of all the myelograms obtained in 2016 at 2 affiliated hospitals. At hospital A, seizure threshold-lowering medications are discontinued before myelography, and prophylactic diazepam is given for all cervical myelograms. At hospital B, seizure threshold-lowering medications are not withheld before the procedure, and medical seizure prophylaxis is not implemented. The seizure threshold-lowering medications the patients were taking at the time of the procedure and postmyelographic seizure incidence were documented.

RESULTS: A total of 311 patients underwent myelography during 2016. One hundred eleven patients (36\%) were on at least 1 seizure threshold-lowering medication, and 30 (10\%) were on at least 2. The most common medications were duloxetine, sertraline, venlafaxine, bupropion, and trazodone. The most common tricyclic antidepressant was amitriptyline. Three patients across both sites had a controlled seizure disorder and were on antiepileptics. None of the patients at either hospital had seizures during or within 3 hours following any of the myelograms during the study period.

CONCLUSIONS: Continuing seizure threshold-lowering medications during myelography does not increase the risk of seizures. Screening for and withholding seizure threshold-lowering medications are not indicated for routine myelography.

ABBREVIATIONS: STLM = seizure threshold-lowering medication; TCA = tricyclic antidepressant

M yelography remains a useful diagnostic procedure to evaluate spinal disease, especially in patients with contraindications to MR imaging. ${ }^{1}$ The risks of myelography are related to the lumbar puncture itself and the intrathecal administration of contrast. ${ }^{2}$ Iodinated contrast agents used for myelography have been in use for $>90$ years. The earliest agents such as iodophendylate were oil-based and not readily resorbed from the CSF, and the oil residue caused arachnoid adhesions in 3 of 4 patients who received the agent. ${ }^{3}$ The first water-soluble myelographic contrast

Received January 30, 2019; accepted after revision March 10.

From the Department of Radiology, Eastern Virginia Medical School, Norfolk, Virginia.

Paper previously presented, in part, at: Annual Meeting of the American Society of Neuroradiology and the Foundation of the ASNR Symposium, June 4-7, 2018: Vancouver, British Columbia, Canada.

Please address correspondence to Frank Mihlon, MD, Eastern Virginia Medical School, Department of Radiology, 600 Gresham Dr, Norfolk, Virginia 23507; e-mail: frank@mihlon.com; @frankmihlon

http://dx.doi.org/10.3174/ajnr.A6027 agents were introduced in the early 1970s, and of these, metrizamide gained mainstream adaptation. Metrizamide compared favorably with iodophendylate because it resorbed with the CSF, but it was well-known to carry a non-negligible risk of neurologic symptoms, including seizure, with intrathecal administration. ${ }^{4}$ Since the advent of second-generation, nonionic water-soluble contrast agents such as iohexol, myelography-related seizure activity has become a very rare event. There have been only scattered individual case reports of seizures occurring in patients undergoing myelography with these agents, and most of these case reports had extenuating circumstances such as a history of epilepsy or an overdosage of the intrathecal contrast agent. ${ }^{5-8}$ Nonetheless, the published guidelines for clinical practice surrounding myelography have changed little since the transition from metrizamide to second-generation, nonionic water-soluble contrast agents.

The American College of Radiology-American Society of Neuroradiology-Society of Pediatric Radiology clinical practice guidelines recommend screening patients' medications and dis- 
continuing those that may lower the seizure threshold. ${ }^{1}$ The guidelines advise withholding seizure threshold-lowering medications (STLMs) for 48 hours pre- and 24 hours postmyelography. However, institutional and individual practices vary widely in their adherence to these recommendations. In 2005, 63\% of practitioners screened for STLMs. ${ }^{9}$ In 2018 , only $43 \%$ of practitioners screened for such medications. ${ }^{10}$ Decreased adherence to these recommendations is likely attributable to increased familiarity with the newer contrast agents. Furthermore, $>100$ medications fall into the category of STLMs. Identifying and withholding such medications before myelography and then resuming them after the procedure are laborious clinical tasks and are anxiety-provoking for the patient. In addition, referring clinicians and patients can become frustrated by such requirements, particularly when they result in delaying or rescheduling of procedures. In a study on the emotional implications of cancelled pediatric outpatient operations, $45 \%$ of parents were "disappointed" and $16 \%$ were "frustrated" by the cancellation. ${ }^{11}$

This investigation is a retrospective observational study comparing the policies surrounding STLM continuation during myelography at 2 large hospitals (Sentara Norfolk General Hospital and Sentara Virginia Beach General Hospital) within the same institutional network and the associated myelography-induced seizure rates. The 2 hospitals have different radiology groups and different policies surrounding the continuation of outpatient STLM regimens during myelography, but the contrast agent used and other circumstances such as postmyelography care are otherwise the same. The purpose of this study was to determine whether there is a difference in the incidence of seizures between these 2 sites and, as a consequence, whether allowing patients to continue to take their outpatient STLM regimens during myelography affects the rate of myelography-induced seizures.

\section{MATERIALS AND METHODS}

Following institutional review board approval at Eastern Virginia Medical School, a retrospective chart review was conducted on all the patients who underwent myelography in 2016 at 2 hospitals in a single institutional network. At hospital A (Sentara Virginia Beach General Hospital), patients are screened for STLMs, and they are discontinued 48 hours before the myelography and resumed 48 hours after the procedure. Prophylactic diazepam is given for all cervical myelograms. At hospital B (Sentara Norfolk General Hospital), patients are not screened for STLMs, no changes are made to patients' medication regimens, and no diazepam is given for seizure prophylaxis. All myelograms were obtained with Omnipaque (iohexol; GE Healthcare, Piscataway, New Jersey) intrathecal contrast. Administered doses varied with procedure level, with cervical and total spine myelograms using, on average, $10 \mathrm{~mL}$ of iohexol, $300 \mathrm{mg} \mathrm{I} / \mathrm{mL}$, and lumbar myelograms using, on average, $16 \mathrm{~mL}$ of iohexol, $180 \mathrm{mg} \mathrm{I} / \mathrm{mL}$. Administered doses for thoracic myelograms varied with regard to contrast concentration and volume. Anticoagulants were managed in the same manner at both sites and discontinued before the procedure.

Demographic information (age at the procedure, sex), type of myelogram (total spine, cervical, thoracic, or lumbar), contrast agent and volume used, list of medications at the time of the
Table 1: Demographic information of all patients undergoing myelography in $\mathbf{2 0 1 6}$ at the 2 sites

\begin{tabular}{lcc}
\hline & Screened/Held & Not Screened/Held \\
\hline Sex & & \\
Male & 81 & 78 \\
Female & 87 & 65 \\
Age (yr) & & \\
Median & 58.5 & 57 \\
Mean & $57.4 \pm 14$ & $56.9 \pm 12$ \\
Minimum & 24 & 24 \\
Maximum & 87 & 85 \\
Myelogram & & \\
Cervical & 34 & 40 \\
Thoracic & 1 & 3 \\
Lumbar & 121 & 61 \\
Multilevel $(>1$ level) & 12 & 39 \\
Seizures & 0 & 0 \\
\hline
\end{tabular}

myelography, and the presence or absence of seizures during or within 3 hours after the procedure were recorded. STLMs were defined according to the Omnipaque package insert: "Phenothiazine derivatives... MAO inhibitors, tricyclic antidepressants, CNS stimulants, and psychoactive drugs described as analeptics, major tranquilizers, or antipsychotic drugs." 12

\section{RESULTS}

Between hospitals A and B, a total of 311 patients underwent myelography during 2016 (Table 1). One hundred sixty-eight myelograms were obtained at hospital A, which screens and holds STLMs for myelography, and 143 myelograms were obtained at hospital B, which does not screen and hold STLMs for myelography. At hospital A, 43 (26\%) patients undergoing myelography were on an outpatient regimen that included at least 1 STLM, and these were withheld for 48 hours before and following myelography. At hospital B, 68 (48\%) patients were on an outpatient regimen that included at least 1 STLM, and these patients underwent myelography without having the medications withheld.

There were no significant differences in age $(P=.094)$ or sex $(P=.266)$ between the 2 patient populations. The distribution of the types of myelograms performed at the 2 hospitals varied, with hospital A performing more lumbar myelograms and hospital B performing more total spine myelograms. There were no reported seizures during or within 3 hours of any of the myelograms at either of the 2 hospitals.

The neurologic medication most frequently used by patients was duloxetine ( 26 patients, $8 \%$ ), followed by sertraline and venlafaxine (Table 2). The most frequently used tricyclic antidepressant (TCA) was amitriptyline. Other infrequently encountered TCAs were nortriptyline, amoxapine, and imipramine. In total, 13 (4\%) patients were on a TCA. Additionally, $13(4 \%)$ patients were on bupropion at the time of myelography. Six patients were taking 1 antiepileptic medication (4 at the screened site, 2 at the nonscreened site). Medications included carbamazepine, levetiracetam, and lamotrigine. Three of these patients had a documented seizure disorder ( 2 at the screened site, 1 at the nonscreened site). One of these patients, who was part of the nonscreened group, was taking amitriptyline concurrently. The remaining 3 patients were taking lamotrigine for bipolar disorder and chronic pain.

AJNR Am J Neuroradiol 40:916-19 May 2019 www.ajnr.org 
Table 2: Frequency of neurologic medications reported in patients undergoing myelography at the 2 sites

\begin{tabular}{llccc}
\hline \multicolumn{1}{c}{ Medication } & \multicolumn{1}{c}{ Class } & Total & $\begin{array}{c}\text { Screened/ } \\
\text { Held }\end{array}$ & $\begin{array}{c}\text { Not } \\
\text { Screened/ } \\
\text { Held }\end{array}$ \\
\hline Duloxetine & SNRI & 26 & 11 & 15 \\
Sertraline & SSRI & 18 & 4 & 14 \\
Venlafaxine & SNRI & 16 & 7 & 9 \\
Bupropion & Mixed & 13 & 5 & 8 \\
Trazodone & Mixed & 11 & 7 & 4 \\
Amitriptyline & TCA & 10 & 2 & 8 \\
Fluoxetine & SSRI & 10 & 3 & 7 \\
Paroxetine & SSRI & 10 & 5 & 5 \\
Citalopram & SSRI & 7 & 4 & 3 \\
Escitalopram & SSRI & 6 & 3 & 3 \\
Quetiapine & Antipsychotic & 4 & 2 & 2 \\
Desvenlafaxine & SNRI & 3 & 0 & 3 \\
Lurasidone & Antipsychotic & 2 & 1 & 1 \\
Mirtazapine & Mixed & 1 & 0 & 1 \\
Nortriptyline & TCA & 1 & 0 & 1 \\
Amoxapine & TCA & 1 & 0 & 1 \\
Imipramine & TCA & 1 & 1 & 0 \\
Fluvoxamine & SSRI & 1 & 1 & 0 \\
Risperidone & Antipsychotic & 1 & 1 & 0 \\
\hline Note- & & & 2 & \\
\hline
\end{tabular}

Note:-SSRI indicates selective serotonin reuptake inhibitors; SNRI, serotonin and norepinephrine reuptake inhibitors.

\section{DISCUSSION}

In the earlier days of medical imaging, myelography was the only way to image spinal neural impingement. The advent of MR imaging brought with it the ability to image the spinal neural structures without the need for an invasive procedure, and subsequently, it largely replaced myelography as the diagnostic test of choice for spinal neural impingement. Today, many patients undergo myelography because they are precluded from MR imaging, either due to safety reasons, such as having a pacemaker or claustrophobia, or due to artifacts from surgical hardware. ${ }^{1}$ Myelography is also commonly used in instances in which the myelographic data are superior to data portrayed by MR imaging. These specific situations include localization of the site of a CSF leak in cases of intracranial hypotension; some instances of surgical planning, particularly in the case of a failing fusion construct; and in cases of dynamic/positional neural impingement, which can be diagnosed during the fluoroscopic portion of the examination.

The first generation of water-soluble nonionic contrast agents, primarily metrizamide with regard to contrast use in myelography, exhibited evidence of neurotoxicity and include many described episodes of encephalopathy, seizures, and other neurologic manifestations. ${ }^{8}$ Iohexol is a second-generation water-soluble nonionic contrast agent approved by the Food and Drug Administration for myelography in the mid-1980s and was the contrast agent used in this retrospective observational study. Studies comparing iohexol with metrizamide have shown that iohexol causes significantly less frequent and less severe adverse reactions than metrizamide. ${ }^{13}$ In a parallel, double-blind, randomized study comparing iohexol and metrizamide in 60 consecutive patients undergoing lumbar myelography, iohexol did not produce any epileptiform activity, but epileptiform activity was detected in 5 patients receiving metrizamide. ${ }^{14}$ In another double-blind comparative study of 30 patients undergoing cervical myelography, pyramidal signs and seizures occurred only after metrizamide myelography. ${ }^{15}$ It is unclear why iohexol has a lower risk of seizures compared with metrizamide. This may be due to the lower penetration of iohexol into the central nervous system structures. Unlike metrizamide, which has a glucose side chain, iohexol presumably does not interfere with glucose metabolism in the brain. ${ }^{8}$

There are only a few case reports describing seizures in patients undergoing myelography with iohexol. ${ }^{16-19}$ Alimohammadi et $\mathrm{al}^{16}$ reported generalized tonic-clonic seizure in a 48 -year-old man who underwent outpatient lumbar myelography using 18 $\mathrm{mL}$ of iohexol, $240 \mu \mathrm{g} / \mathrm{mL}$, which ultimately resulted in death. Kertmen et $\mathrm{al}^{18}$ reported postprocedural generalized tonic-clonic seizure after $3 \mathrm{~mL}$ of iohexol was inadvertently injected intrathecally during an outpatient transforaminal percutaneous endoscopic lumbar discectomy for a lumbar disc herniation in a 20year-old woman. Rosenberg and Grant ${ }^{19}$ reported a 52-year-old man who developed a generalized tonic-clonic seizure 30 minutes after lumbar myelography with iohexol (dose not specified) and who subsequently developed a malignant hyperthermia-like syndrome. In all these cases, patients were not taking any prescription medications; therefore, screening for STLMs before the procedure would not have changed the clinical outcome.

Despite the tenuous evidence of a significant risk of seizures with intrathecal administration of second-generation water-soluble nonionic contrast agents, the current guidelines provided both by the relevant medical societies ${ }^{1}$ and in the iohexol package insert $^{12}$ recommend screening and withholding STLMs for myelography. These seizure-conscious guidelines could be in response to the cited case reports but also may simply reflect a holdover from the days of metrizamide. When neuroradiologists decide whether to implement the guidelines in their own medical practice, they must weigh the effect on their patients. Discontinuing STLMs temporarily may cause antidepressant discontinuation syndrome and increase the risk of relapse of depression or anxiety, ${ }^{20}$ among other conditions. In addition, hospital systems, referring clinicians, and radiologists alike can get frustrated with screening and holding the ever-growing list of STLMs because miscommunications and other potential breakdowns of that process can result in otherwise needlessly rescheduling or cancelling appropriate myelographic procedures.

Interestingly, the data suggest that more than half of practicing neuroradiologists have decided that the societally recommended screen-and-hold approach is indeed not best for their clinical practice. In a 2018 survey of 700 American Society of Neuroradiology members, only $43 \%$ of respondents reported screening for STLMs. ${ }^{10}$ A mere $3 \%$ reported having had a patient experience a postprocedural seizure during their entire personal history of clinical myelography practice. There was no statistically significant difference in postmyelographic seizures between practices that discontinued STLMs and those that did not. A similar surveybased study performed in 2005 found that $63 \%$ of practitioners screened for STLMs at that time, ${ }^{9}$ indicating that across time, the screen-and-hold practice is falling out of favor among neuroradiologists.

Our investigation, a retrospective observational study comparing the policies surrounding STLM continuation during myelography at 2 large hospitals within the same institutional net- 
work, showed that no seizures occurred in either the 168 patients who had their STLMs screened and held for myelography or the 143 patients who were allowed to continue their STLM outpatient regimen. Perhaps the most interesting number produced by our study is the 68 patients at hospital B who were on at least 1 STLM as an outpatient and were allowed to continue their medical regimen during myelography; there were no postmyelography seizures in this supposedly higher risk group. This finding supports the notion that the current second-generation, nonionic contrast agents do not present a significant risk of seizure when used for myelography, even when allowing patients to continue their outpatient STLM regimens in the time surrounding the procedure. This finding is in line with the survey data that show that the currently recommended screen-and-hold approach to STLMs for myelography is increasingly not being used by neuroradiologists who perform myelography as they become more familiar with the current generation of contrast agents.

Our study has several limitations, mainly the low sample size and the retrospective nature of the investigation. Given the rare occurrence of myelography-related seizures using the current generation of contrast agents, the sample number that would be needed to find a seizure, even retrospectively, would have to be prohibitively large and would likely not achieve statistical significance in terms of establishing causation. The sample size that would be required to achieve statistical significance even to answer the question of noninferiority would similarly be prohibitively large. Thus, retrospective-type reviews like ours and surveys will, in all likelihood, remain the type of data on which the relevant societies will have to rely to make recommendations surrounding the issue of STLMs and myelography. With regard to limitations peculiar to our study, it is odd that there was such a discrepancy in the percentage of patients who were on STLMs at one hospital versus the other (26\% versus $48 \%$ ). One could speculate as to the innumerable potential reasons for this finding, from patient population to the accuracy of patient reporting, but it is, nonetheless, fortuitous in terms of the meaningfulness of our study that the larger group of individuals on STLMs was at hospital B, which does not screen and hold STLMs for myelography and is functionally the experimental group in this investigation.

\section{CONCLUSIONS}

We found no evidence that continuing STLMs such as TCAs and selective serotonin reuptake inhibitors during myelography presents an increased risk of seizures. The reported benefits of screening for such medications are anecdotal and based on studies using older neurotoxic contrast agents, mainly metrizamide. In line with the reports of the changing practice patterns and in lieu of high-level prospective studies, our single-institution retrospective observational study supports the growing body of literature that suggests that screening for and holding STLMs is not indicated for routine myelography.

\section{REFERENCES}

1. ACR-ASNR-SPR Practice Parameter for the Performance Myelography and Cisternography. https://www.acr.org/-/media/ACR/Files/ Practice-Parameters/Myelog-Cisternog.pdf. Accessed December 21, 2018

2. Eames FA, Cloft HJ. Discontinuing patient medications prior to myelography. AJR Am J Roentgenol 2005;184:695 CrossRef Medline

3. Johnson AJ, Burrows EH. Thecal deformity after lumbar myelography with iophendylate (Myodil) and meglumine iothalamate (Conray 280). Br J Radiol 1978;51:196-202 CrossRef Medline

4. Killebrew K, Whaley RA, Hayward JN, et al. Complications of metrizamide myelography. Arch Neurol 1983;40:78-80 CrossRef Medline

5. Lipman JC, Wang AM, Brooks ML, et al. Seizure after intrathecal administration of iopamidol. AJNR Am J Neuroradiol 1988;9: 787-88 Medline

6. Klein KM, Shiratori K, Knake S, et al. Status epilepticus and seizures induced by iopamidol myelography. Seizure 2004;13:196-99 CrossRef Medline

7. Simon JH, Ekholm SE, Kido DK, et al. High-dose iohexol myelography. Radiology 1987;163:455-58 CrossRef Medline

8. Fedutes BA, Ansani NT. Seizure potential of concomitant medications and radiographic contrast media agents. Ann Pharmacother 2003;37:1506-10 CrossRef Medline

9. Sandow BA, Donnal JF. Myelography complications and current practice patterns. AJR Am J Roentgenol 2005;185:768-71 CrossRef Medline

10. Shah LM, Kranz PG, Anzai Y, et al. Critical assessment of myelography practices: a call for rational guideline revision. AJNR Am J Neuroradiol 2018;39:2378-84 CrossRef Medline

11. Tait AR, Voepel-Lewis T, Munro HM, et al. Cancellation of pediatric outpatient surgery: economic and emotional implications for patients and their families. J Clin Anesth 1997;9:213-19 CrossRef Medline

12. Omnipaque (iohexol) injection [package insert]. Piscataway: GE Healthcare; 2010

13. Hindmarsh T, Ekholm SE, Kido DK, et al. Lumbar myelography with iohexol and metrizamide: a double-blind clinical trial. Acta Radiol Diagn (Stockh) 1984;25:365-68 CrossRef Medline

14. Maly P, Bach-Gansmo T, Elmqvist D. Risk of seizures after myelography: comparison of iohexol and metrizamide. AJNR Am J Neuroradiol 1988;9:879-83 Medline

15. Reisin R, Ethier R, de la Sayette V, et al. Metrizamide compared with iohexol for cervical myelography: a double-blind study. Can Assoc Radiol J 1988;39:107-10 Medline

16. Alimohammadi H, Abdalvand A, Safari S, et al. Status epilepticus after myelography with iohexol (Omnipaque). Am J Emerg Med 2012;30:2092.e1-3 CrossRef Medline

17. Park KS, Moon JY, Oh CS, et al. Acetabular central fracture dislocation after generalized seizure during lumbar myelography with iohexol. Case Rep Orthop 2013;2013:190917 CrossRef Medline

18. Kertmen H, Gürer B, Yilmaz ER, et al. Postoperative seizure following transforaminal percutaneous endoscopic lumbar discectomy. Asian J Neurosurg 2016;11:450 CrossRef Medline

19. Rosenberg H, Grant M. Ascending tonic-clonic syndrome secondary to intrathecal Omnipaque. J Clin Anesth 2004;16:299-300 CrossRef Medline

20. Gabriel M, Sharma V. Antidepressant discontinuation syndrome. CMAJ 2017;189:E747 CrossRef Medline 